\title{
WEAK AND STRONG CONVERGENCE THEOREMS OF ALGORITHMIC SCHEMES FOR THE MULTIPLE-SETS SPLIT FEASIBILITY PROBLEM
}

Nguyen Buong ${ }^{1}$, Nguyen Duong Nguyen ${ }^{2 *}$

${ }^{1}$ Institute of Theoretical and Applied Research

Faculty of Information Technology, Duy Tan University

Vietnam Academy of Science and Technology, Institute of Information Technology,

${ }^{2}$ Foreign Trade University

\section{ARTICLE INFO}

Received: 26/9/2021

Revised: 05/11/2021

Published: 05/11/2021

KEYWORDS

Nonexpansive mapping

Fixed point

Metric projection

Multiple-sets split feasibility problem

String-averaged algorithmic scheme

\begin{abstract}
In this paper, for solving the multiple-sets split feasibility problem (MSSFP) in Hilbert spaces, we present a general approach to design iterative methods. We propose a weak convergence stringaveraged algorithmic scheme and a strong convergence stringaveraged algorithmic scheme. The strong convergence string averaged algorithmic scheme is constructed based on the general iterative method for nonexpansive mappings, in which the stepsize is computed directly in each iteration without the knowledge of the operator norm. These algorithmic schemes contain not only improvement modifications of the well known cyclic and simultaneous iterative methods as particular cases but also new ones.
\end{abstract}

\section{CÁC ĐINH LÝ HộI TƯ YẾU VÀ HộI TỤ MẠNH}

CỦA CÁC LƯợC Đồ THUUẬT TOÁN CHO

BÀI TOÁN CHẤP NHẬN TÁCH ĐA TậP

Nguyễn Bường ${ }^{1}$, Nguyễn Dương Nguyễn ${ }^{2 *}$

${ }^{1}$ Viện Nghiên cứu Lý thuyết và Ứng dụng,

Khoa Công nghệ thông tin, Dại học Duy Tân

Viên Công nghệ thông tin, Viện Hàn lâm Khoa học và Công nghệ Việt Nam,

${ }^{2}$ Trường Dại học Ngoại thương

\begin{tabular}{|c|c|}
\hline THÔNG TIN BÀI BÁO & TÓM TẮT \\
\hline $\begin{array}{l}\text { Ngày nhận bài: 26/9/2021 } \\
\text { Ngày hoàn thiện: 05/11/2021 } \\
\text { Ngày đăng: 05/11/2021 }\end{array}$ & $\begin{array}{l}\text { Trong bài báo này, để giải bài toán chấp nhận tách đa tập } \\
\text { (MSSFP) trong không gian Hilbert, chúng tôi trình bày một cách } \\
\text { tiếp cận tổng quát để xây dựng các phương pháp lặp. Chúng tôi }\end{array}$ \\
\hline TỪ KHÓA & dề xuất một lược đồ thuật toán xâu trung bình với sự hội tụ yếu \\
\hline $\begin{array}{l}\text { Ánh xạ không giãn } \\
\text { Điểm bất động } \\
\text { Phép chiếu metric } \\
\text { Bài toán chấp nhận tách đa tập } \\
\text { Lược đồ thuật toán xâu trung bình }\end{array}$ & $\begin{array}{l}\text { và một lược đồ thuật toán xâu trung bình với sự hội tụ mạnh. } \\
\text { Lược đồ thuật toán xâu trung bình với sự hội tụ mạnh được xây } \\
\text { dựng dựa trên phương pháp lặp tổng quát cho ánh xạ không giãn, } \\
\text { trong đó cỡ bước được tính toán trực tiếp trong mỗi bước lặp mà } \\
\text { không cần sử dụng chuẩn của toán tử. Những lược đồ thuật toán } \\
\text { này không chỉ bao hàm những cải tiến của phương pháp lặp vòng } \\
\text { và lặp đồng thời đã biết như những trường hợp riêng mà còn bao } \\
\text { hàm cả những phương pháp lặp mới. }\end{array}$ \\
\hline
\end{tabular}

DOI: https://doi.org/10.34238/tnu-jst.5084

*Corresponding author. Email: duongnguyen@ftu.edu.vn 


\section{Introduction and preliminaries}

Let $I=\{1,2, \cdots, N\}$ and $J=\{1,2, \cdots, M\}$ with any fixed positive integers $N$ and $M$. Let $H_{1}$ and $H_{2}$ be two real Hilbert spaces with $\left\{C_{i}\right\}_{i \in I}$ and $\left\{Q_{j}\right\}_{j \in J}$ being two families of closed convex subsets in $H_{1}$ and $H_{2}$, respectively. Let $A$ be a bounded linear mapping from $H_{1}$ into $H_{2}$ with the norm denoted by $\|A\|$. We use the symbol $E,\langle\cdot, \cdot\rangle$ and $\|\cdot\|$ to define the identity mapping, an inner product and a norm, respectively, in any Hilbert space.

The MSSFP is to find a point

$$
p \in C:=\cap_{i \in I} C_{i} \quad \text { such that } \quad A p \in Q:=\cap_{j \in J} Q_{j}
$$

Denote by $\Gamma$ the set of solutions for (1.1). Throughout this paper, we assume that $\Gamma \neq \emptyset$. This problem was first introduced by Censor and Elfving [1] for modeling inverse problems that arise from phase retrievals and in image reconstruction [2],[3]. Recently, the MSSFP can also be used to model the intensity-modulated radiation therapy [4], [5].

For solving the split feasibility problem, that is (1.1) with $N=M=1$, Byrne [2], [3] introduced a well-known iterative method, named CQ-method and defined by

$$
x^{k+1}=P_{C}\left(E-\gamma A^{T}\left(E-P_{Q}\right) A\right) x^{k}, k \geq 1,
$$

with a fixed real number $\gamma \in\left(0,2 /\|A\|^{2}\right)$, where $P_{C}$ and $P_{Q}$ denote the metric projections on the sets $C$ and $Q$, respectively, and $A^{T}$ stands for the transpose of $A$.

Up to now, there is a long list of works concerning iterative methods to solve (1.1), for example, see [6]-[13] and references therein. These methods are extensions and modifications of (1.2) in different directions. In many works, ones used the gradient of a proximity function, that measures the distance of a point to all the sets in the image space, to construct iterative methods. Among them, there are two important ones, the first of which is the cyclic iterative method,

$$
x^{k+1}=P_{C_{m(k)}}\left(E-\gamma \sum_{j=1}^{M} \eta_{j} A^{*}\left(E-P_{Q_{j}}\right) A\right) x^{k},
$$

where $m(k)=k \bmod (N+1), \eta_{j}>0$ for every $1 \leq j \leq M$ and $A^{*}$ denotes the adjoint of $A$. Another method is the simultaneous iterative one,

$$
x^{k+1}=\sum_{i=1}^{N} \beta_{i} P_{C_{i}}\left(E-\gamma \sum_{j=1}^{M} \eta_{j} A^{*}\left(E-P_{Q_{j}}\right) A\right) x^{k},
$$

where $\beta_{i}>0$ for all $i$ such that $\sum_{i=1}^{N} \beta_{i}=1$ and $0<\gamma<2 / \tilde{L}$ with $\tilde{L}=\|A\|^{2} \sum_{j=1}^{M} \eta_{j}$. Xu [10] showed that (1.3) and (1.4) converge weakly to an element in $\Gamma$. Recently, Buong [6] proposed two weakly convergent improvement modifications of (1.3) and (1.4) with two new iterative methods, described in a general form,

$$
x^{k+1}=P_{1}\left(E-\gamma A^{*}\left(E-P_{2}\right) A\right) x^{k},
$$

where $P_{1}=P_{C_{1}} \cdots P_{C_{N}}$ or $P_{1}=\sum_{i=1}^{N} \beta_{i} P_{C_{i}}$ and $P_{2}=P_{Q_{1}} \cdots P_{Q_{M}}$ or $P_{2}=\sum_{j=1}^{M} \eta_{j} P_{Q_{j}}$, with positive real numbers $\beta_{i}$ and $\eta_{j}$, satisfying $\sum_{i=1}^{N} \beta_{i}=\sum_{j=1}^{M} \eta_{j}=1$.

In the case that $H_{1} \equiv H_{2}$ and $A=E$, the MSSFP deduces to the convex feasibility problem (CFP), that is to find a point $p \in C$. To solve the CFP, Censor et al. [14] proposed an algorithmic scheme in which the end-points of strings of sequential projections onto the constraints are averaged.

In Section 2, motivated by the results in the works above, we introduce two algorithmic schemes that contains the algorithm (1.5) and new others as particular cases. Specifically, in Section 2.1, for solving (1.1), we propose a new weak convergence string-averaged algorithmic scheme. In Section 2.2, in order to obtain the strong convergence, based on the general iterative method for nonexpansive mappings [15], we give a new general string-averaged algorithmic scheme with a self-adaptive step-size. 
First, we list some facts that will be used in the proof of our results.

Definition 1.1 A mapping $T$ from a subset $C$ of a Hilbert space $H$ into $H$ is called:

(i) $\theta$-Lipschitz continuous with a Lipschitz constant $\theta \in[0, \infty)$ if $\|T x-T y\| \leq \theta\|x-y\|$ for all $x, y \in C$ and nonexpansive if $\theta=1$;

(ii) $\gamma$-inverse strongly monotone if $\gamma\|T x-T y\|^{2} \leq\langle T x-T y, x-y\rangle$ for all $x, y \in C$ where $\gamma$ is a positive number and firmly nonexpansive if $\gamma=1$;

(iii) averaged, if $T=(1-\alpha) E+\alpha U$ for some fixed $\alpha \in(0,1)$ and a nonexpansive mapping $U$ and we say $T$ is $\alpha$-averaged;

(iv) $\eta$-strongly monotone and $\gamma$-strictly pseudocontractive, if it satisfies, respectively, the conditions, $\left\langle T x_{1}-T x_{2}, x_{1}-x_{2}\right\rangle \geq \eta\left\|x_{1}-x_{2}\right\|^{2}$ and $\left\langle T x_{1}-T x_{2}, x_{1}-x_{2}\right\rangle \leq\left\|x_{1}-x_{2}\right\|^{2}-$ $\gamma\left\|(E-T) x_{1}-(E-T) x_{2}\right\|^{2}$, for all $x_{1}, x_{2} \in C, \eta$ and $\gamma$ are some positive real numbers.

For a closed convex subset $C$ of $H$, there exists a mapping $P_{C}$ from $H$ onto $C$ such that $\left\|P_{C} x-x\right\|=\inf _{y \in C}\|y-x\|$ for each $x \in H$. The mapping $P_{C}$ is called the metric projection on $C$. We know that $P_{C}$ is firmly nonexpansive (hence, nonexpansive) and (1/2)-averaged. Moreover, $\left\|x-P_{C} x\right\|^{2}+\left\|P_{C} x-z\right\|^{2} \leq\|x-z\|^{2}, x \in H, z \in C$. We denote by $\operatorname{Fix}(T)=$ $\{x \in C: T x=x\}$, the set of fixed points for a mapping $T$.

Lemma 1.1 ([16]) Let $H$ be any real Hilbert space, let $T_{i}$ be an $\alpha_{i}$-averaged mapping with $\alpha_{i}>0$ for each $i \in\{1,2, \cdots, S\}$ and let $\omega=\left(\omega_{1}, \omega_{2}, \cdots, \omega_{S}\right)$ be a positive real vector such that $\sum_{i=1}^{S} \omega_{i}=1$. Set $T=\sum_{i=1}^{S} \omega_{i} T_{i}$ and $\alpha=\sum_{i=1}^{S} \omega_{i} \alpha_{i}$. Then, $T$ is $\alpha$-averaged. Moreover, $\tilde{T}=T_{S} T_{S-1} \cdots T_{1}$ is $\tilde{\alpha}$-averaged with $\tilde{\alpha}=1 /\left(1+1 / \sum_{i=1}^{S} \alpha_{i} /\left(1-\alpha_{i}\right)\right)$ and $\operatorname{Fix}(T)=\operatorname{Fix}(\tilde{T})=$ $\cap_{i=1}^{S} \operatorname{Fix}\left(T_{i}\right)$.

Lemma 1.2 ([17]) Let $C$ be a closed convex subset of a real Hilbert space $H$ and let $T: C \rightarrow C$ be a nonexpansive mapping with $\operatorname{Fix}(T) \neq \emptyset$. If $\left\{z^{l}\right\}$ is a sequence in $C$ weakly converging to $x$ and if $\left\{(E-T) z^{l}\right\}$ converges strongly to $y$, then $(E-T) x=y$. In particular, if $y=0$, then $x \in \operatorname{Fix}(T)$.

Lemma 1.3 ([18]) Let $\left\{a_{k}\right\}$ and $\left\{c_{k}\right\}$ be sequences of real numbers, having the properties: $a_{k+1} \leq\left(1-t_{k}\right) a_{k}+t_{k} c_{k}, a_{k} \geq 0, \limsup _{k \rightarrow \infty} c_{k} \leq 0$ and $t_{k}$ satisfies condition

$(t): t_{k} \in(0,1)$ for all $k \geq 1, \lim _{k \rightarrow \infty} t_{k}=0$ and $\sum_{k=1}^{\infty} t_{k}=\infty$.

Then, $\lim _{k \rightarrow \infty} a_{k}=0$.

Lemma 1.4 ([19]) Let $H$ be a real Hilbert space and let $F: H \rightarrow H$ be an $\eta$-strongly monotone and $\gamma$-strictly pseudocontractive mapping with $\eta+\gamma>1$. Then, for any $t \in(0,1), E-t F$ is contractive with constant $1-t \tau$ where $\tau=1-\sqrt{(1-\eta) / \gamma}$.

Lemma 1.5 ([20]) Let $\left\{a_{k}\right\}$ be a sequence of real numbers with a subsequence $\left\{k_{l}\right\}$ of $\{k\}$ such that $a_{k_{l}}<a_{k_{l}+1}$ for all integer numbers $l \geq 1$. Then, there exists a nondecreasing sequence $\left\{m_{k}\right\} \subseteq\{k\}$ such that $m_{k} \rightarrow \infty, a_{m_{k}} \leq a_{m_{k}+1}$ and $a_{k} \leq a_{m_{k}+1}$ for all (sufficiently large) integer numbers $k \geq 1$. In fact, $m_{k}=\max \left\{l \leq k: a_{l} \leq a_{l+1}\right\}$.

\section{Main results}

\subsection{String-averaged algorithmic scheme for the multiple-sets split feasibility prob- lem}

Let the string $I_{t}=\left(i_{1}^{t}, i_{2}^{t}, \cdots, i_{\gamma\left(I_{t}\right)}^{t}\right)$ be a finite nonempty subset of $I$, for every $t=1,2, \cdots, S_{1}$, where the length of the string $I_{t}$, denoted by $\gamma\left(I_{t}\right)$, is the number of elements in $I_{t}$. Put $T_{t}^{1}:=P_{i_{\gamma\left(I_{t}\right)}^{t}} \cdots P_{i_{2}^{t}} P_{i_{1}^{t}}$, where $P_{i_{l}^{t}}=P_{C_{i}^{t}}$, for $l=1,2, \cdots, \gamma\left(I_{t}\right)$ and $t=1,2, \cdots, S_{1}$. Given a positive weight vector $\beta=\left(\beta_{1}, \beta_{2}, \cdots, \beta_{S_{1}}\right)$ with $\sum_{t=1}^{S_{1}} \beta_{t}=1$, we define the algorithmic mapping $\mathcal{P}_{1}:=\sum_{t=1}^{S_{1}} \beta_{t} T_{t}^{1}$. We suppose that every element of $I$ appears in at least 
one of the string $I_{t}$. Analogously, for the family $\left\{Q_{j}\right\}_{j \in J}$, we can construct the mapping $\mathcal{P}_{2}:=\sum_{t=1}^{S_{2}} \eta_{t} T_{t}^{2}$ where $T_{t}^{2}:=P_{j_{\gamma\left(J_{t}\right)}^{t}} \cdots P_{j_{2}^{t}} P_{j_{1}^{t}}, P_{j_{l}^{t}}=P_{Q_{j_{l}^{t}}}$ for $t=1,2, \cdots, S_{2}, l=1,2, \cdots, \gamma\left(J_{t}\right)$ and $\eta=\left(\eta_{1}, \eta_{2}, \cdots, \eta_{S_{2}}\right)$ is also a positive weight vector such that $\sum_{t=1}^{S_{2}} \eta_{t}=1$.

First, we need to prove the following lemma.

Lemma $2.1 z \in \Gamma$ if and only if $\left(E-\mathcal{P}_{1}\right) z=A^{*}\left(E-\mathcal{P}_{2}\right) A z=0$. Moreover, the last equality holds if and only if $\left(E-\mathcal{P}_{2}\right) A z=0$.

Proof. Clearly, when $z \in \Gamma$, we have that $z \in C_{i}$ and $A z \in Q_{j}$ for every $i \in I$ and $j \in J$. Consequently, for all $t=1,2, \cdots, S_{1}$ we have that $T_{t}^{1} z=z$ and for $t=1,2, \cdots, S_{2}$, $T_{t}^{2} A z=A z$. From the last two equalities and the properties of $\beta_{t}$ and $\eta_{t}$ it follows $\left(E-\mathcal{P}_{1}\right) z=$ $A^{*}\left(E-\mathcal{P}_{2}\right) A z=0$. Inversely, we have to prove that if $z$ satisfies the equalities then $z \in \Gamma$. Take any point $p \in \Gamma$. It is easy to see that

$$
\|z-p\|^{2}=\left\|\mathcal{P}_{1} z-p\right\|^{2} \leq \sum_{t=1}^{S_{1}} \beta_{t}\left\|T_{t}^{1} z-p\right\|^{2} \leq\|z-p\|^{2}-\sum_{t=1}^{S_{1}} \beta_{t} \sum_{l=1}^{\gamma\left(I_{t}\right)}\left\|U^{i_{l}^{t}} z-U^{i_{l-1}^{t}} z\right\|^{2},
$$
where $U^{i_{l}^{t}}=P_{i_{l}^{t}} \cdots P_{i_{2}^{t}} P_{i_{1}^{t}}$ and $U^{i_{0}^{t}}=E$. Therefore, we get that $\left\|U^{i_{l}^{t}} z-U^{i_{l-1}^{t}} z\right\|^{2}=0$ for $l=1,2, \cdots, \gamma\left(I_{t}\right)$, because $\beta_{t}>0$. Taking $l=1$, we obtain that $U^{i_{1}^{t}} z=z$, which together with the case that $l=2$ implies $U_{2}^{i_{2}^{t}} z=z$. Repeating the process for $l=3, \cdots, \gamma\left(I_{t}\right)$, we get that $U^{i_{l}^{t}} z=z$ for $l=3, \cdots, \gamma\left(I_{t}\right)$. Finally, $U^{i_{l}^{t}} z=z$ for $l=1,2, \cdots, \gamma\left(I_{t}\right)$ and $t=1,2, \cdots, S_{1}$. Since each element of $I$ appears in at least one $I_{t}, P_{C_{i}} z=z$ for each $i \in I$. So, in order to finish the proof for the first conclusion, it is sufficient to show that $P_{Q_{j}} A z=A z$ for all $j \in J$. Indeed, from $A^{*}\left(E-\mathcal{P}_{2}\right) A z=0$ and the nonexpansivity of $\mathcal{P}_{2}$, we can write, respectively, that $\mathcal{P}_{2} A z=A z-w$ where $A^{*} w=0$ and

$$
\|A z-A p\|^{2} \geq\left\|\mathcal{P}_{2} A z-\mathcal{P}_{2} A p\right\|^{2}=\|A z-w-A p\|^{2}=\|A z-A p\|^{2}+\|w\|^{2}-2\left\langle A^{*} w, z-p\right\rangle .
$$

Thus, $w=0$. Consequently, $\mathcal{P}_{2} A z=A z$. By the similar argument as the above, we get the first conclusion. For the second conclusion, we need only to prove the case that if $A^{*}\left(E-\mathcal{P}_{2}\right) A z=0$ then $\left(E-\mathcal{P}_{2}\right) A z=0$. Indeed, from the $(1 / 2)$-inverse strongly monotone property of $\left(E-\mathcal{P}_{2}\right)$ [21], we get that

$$
\begin{aligned}
0 \leq(1 / 2)\left\|\left(E-\mathcal{P}_{2}\right) A z\right\|^{2} & \leq\left\langle\left(E-\mathcal{P}_{2}\right) A z-\left(E-\mathcal{P}_{2}\right) A p, A z-A p\right\rangle \\
& =\left\langle A^{*}\left(E-\mathcal{P}_{2}\right) A z, z-p\right\rangle \leq\left\|A^{*}\left(E-\mathcal{P}_{2}\right) A z\right\|\|z-p\|=0 .
\end{aligned}
$$

This completes the proof.

We have the following results.

Theorem 2.1 Let $H_{1}$ and $H_{2}$ be two real Hilbert spaces, let $A: H_{1} \rightarrow H_{2}$ be a bounded linear mapping such that $A \neq 0$. Let $C_{i}$ and $Q_{j}$, for each $i \in I$ and $j \in J$, be closed convex subsets in $H_{1}$ and $H_{2}$, respectively. Assume that $\Gamma \neq \emptyset$. Then, the sequence $\left\{x^{k}\right\}$, defined by Algorithmic scheme 1:

$$
x^{k+1}=T x^{k}, T=\mathcal{P}_{1}\left(E-\gamma A^{*}\left(E-\mathcal{P}_{2}\right) A\right),
$$

where $\gamma \in\left(0,1 /\|A\|^{2}\right)$ is a fixed number, converges weakly to a solution of $(1.1)$, as $k \rightarrow \infty$. Proof. Since $P_{i_{l}^{t}}$, for $l=1,2, \cdots, \gamma\left(I_{t}\right)$, is (1/2)-averaged, by Lemma 1.1, the mapping $T_{t}^{1}$ is $\alpha_{t^{-}}$ averaged with $\alpha_{t}=1 /\left(1+1 / \gamma\left(I_{t}\right)\right)$, and hence, $\mathcal{P}_{1}$ is a $\beta$-averaged mapping with $\beta=\sum_{t=1}^{S_{1}} \beta_{t} \alpha_{t}$. Meantime, since $\mathcal{P}_{2}$ is nonexpansive, by using Lemma 3.3 in [22], the mapping $E-\gamma A^{*}\left(E-\mathcal{P}_{2}\right) A$ is $\eta$-averaged, where $\eta=\gamma\|A\|^{2}$ and $0<\gamma<1 /\|A\|^{2}$. Therefore, again by Lemma 1.1, the mapping $T$ is $\tau$-averaged with $\tau=(\beta+\eta-2 \beta \eta) /(1-\beta \eta)$. Thus, from Lemmas 2.1 and 1.1, we have that $\operatorname{Fix}(T)=\operatorname{Fix}\left(\mathcal{P}_{1}\right) \cap \operatorname{Fix}\left(E-\gamma A^{*}\left(E-\mathcal{P}_{2}\right) A\right)=\operatorname{Fix}\left(\mathcal{P}_{1}\right) \cap \operatorname{Zer}\left(A^{*}\left(E-\mathcal{P}_{2}\right) A\right)=\Gamma$, where $\operatorname{Zer}(B)$ denotes the set of $x$ such that $B x=0$ for any mapping $B$ in $H_{1}$. Further, by using Theorem 2.1 in [3], we get the conclusion.

Remark 2.1 Taking $S_{1}=S_{2}=1$, we have that $\mathcal{P}_{1}=P_{C_{N}} \cdots P_{C_{2}} P_{C_{1}}$ and $\mathcal{P}_{2}=P_{Q_{M}} \cdots P_{Q_{2}} P_{Q_{1}}$. 
When $S_{1}=N$ and $S_{2}=M$ with $\gamma\left(I_{t}\right)=\gamma\left(J_{t}\right)=1$, we obtain that $\mathcal{P}_{1}=\sum_{i=1}^{N} \beta_{i} P_{C_{i}}$ and $\mathcal{P}_{2}=\sum_{j=1}^{M} \eta_{i} P_{Q_{j}}$. Then, the method (2.1) in this case contains (1.5), as particularities.

\subsection{A general string-averaged algorithmic scheme for the multiple-sets split fea- sibility problem}

In this section, in order to obtain the strong convergence, we propose a new algorithmic scheme based on the general iterative method for nonexpansive mappings, introduced by Marino and $\mathrm{Xu}[15]$.

\section{Algorithmic scheme 2:}

Step 1 . Let $x^{1}$ and $\varepsilon_{1}$ be any point in $H_{1}$ and any positive real number, respectively. Set $k:=1$; Step 2. Assume that the $k$ th iterate $x^{k}$ has been constructed. If $\left(E-\mathcal{P}_{1}\right) x^{k}=\left(E-\mathcal{P}_{2}\right) A x^{k}=0$ then stop and $x^{k}$ is a solution of (1.1). Otherwise, compute

$$
u^{k}=\mathcal{P}_{1}\left(E-\gamma_{k} A^{*}\left(E-\mathcal{P}_{2}\right) A\right) x^{k}, x^{k+1}=t_{k} \bar{\gamma} f x^{k}+\left(E-t_{k} F\right) u^{k},
$$

where $\gamma_{k}=\rho_{k} q\left(x^{k}\right) /\left\|A^{*}\left(E-\mathcal{P}_{2}\right) A x^{k}\right\|^{2}$ if $\left(E-\mathcal{P}_{2}\right) A x^{k} \neq 0$ and

$$
\gamma_{k}=\frac{\rho_{k} q\left(x^{k}\right)}{\left(\left\|A^{*}\left(E-\mathcal{P}_{2}\right) A x^{k}\right\|+\varepsilon_{k}\right)^{2}},
$$

if $\left(E-\mathcal{P}_{2}\right) A x^{k}=0$, with $q(x)=(1 / 2) \sum_{t=1}^{S_{2}} \eta_{t}\left\|\left(E-T_{t}^{2}\right) A x\right\|^{2}$, a new proximity function, $f: H_{1} \rightarrow H_{1}$ is a $\theta$-Lipschitz continuous mapping with a Lipschitz constant $\theta \in[0, \infty)$ and $F: H_{1} \rightarrow H_{1}$ is an $\eta$-strongly monotone and $\gamma$-strictly pseudocontractive mapping.

Step 3. Set $k:=k+1$ and go to Step 2 .

We assume parameters $\rho_{k}$ and $\varepsilon_{k}$ for all $k \geq 1$, satisfy, respectively, the following conditions: $(\rho): 0<\rho \leq \rho_{k} \leq \bar{\rho}<2$ and

$(\varepsilon):\left\{\varepsilon_{k}\right\}$ is a bounded sequence of positive real numbers such that $\liminf _{k \rightarrow \infty} \varepsilon_{k}>0$.

For the sake of simplicity, when $\left(E-\mathcal{P}_{1}\right) x^{k} \neq 0$, the next iterate $x^{k+1}$ can be calculated by (2.2) and (2.3) without verifying that $\left(E-\mathcal{P}_{2}\right) A x^{k}$ equal or does not equal to zero.

Theorem 2.2 Let $H_{1}, H_{2}, A, C_{i}$ and $Q_{j}$ with $\Gamma$ be as in Theorem 2.1. Let $f: H_{1} \rightarrow H_{1}$ be a $\theta$-Lipschitz continuous mapping with a Lipschitz constant $\theta \in[0, \infty)$ and let $F: H_{1} \rightarrow H_{1}$ be an $\eta$-strongly monotone and $\gamma$-strictly pseudocontractive mapping such that $\eta+\gamma>1$. Assume that there hold conditions $(\rho),(\varepsilon)$ and $(t), \bar{\gamma} \in(0, \tau / \theta)$ is a fixed number with $\tau=1-\sqrt{(1-\eta) / \gamma}$ when $\theta \neq 0$ and $\bar{\gamma}=0$ when $\theta=0$. Then, the sequence $\left\{x^{k}\right\}$, defined by Algorithmic scheme 2 , converges strongly to a point in $\Gamma$, as $k \rightarrow \infty$.

Proof. We only discuss the case when the algorithm does not stop after finite number of iterates. First, we consider the case when $\theta \neq 0$. We prove that $\left\{x^{k}\right\}$, defined by Algorithmic scheme 2 , is bounded. Take a point $p \in \Gamma$. Then, since $\mathcal{P}_{1}$ and $T_{t}^{2}$ are nonexpansive and $E-T_{t}^{2}$ is (1/2)-inverse strongly monotone [21] for each $t=1,2, \cdots, S_{2}$, we have that

$$
\begin{aligned}
\left\|u^{k}-p\right\|^{2}= & \left\|\mathcal{P}_{1}\left(E-\gamma_{k} A^{*}\left(E-\mathcal{P}_{2}\right) A\right) x^{k}-\mathcal{P}_{1} p\right\|^{2} \leq\left\|x^{k}-p-\gamma_{k} A^{*}\left(E-\mathcal{P}_{2}\right) A x^{k}\right\|^{2} \\
= & \left\|x^{k}-p\right\|^{2}-2 \gamma_{k}\left\langle\left(E-\mathcal{P}_{2}\right) A x^{k}-\left(E-\mathcal{P}_{2}\right) A p, A x^{k}-A p\right\rangle \\
& \quad+\gamma_{k}^{2}\left\|A^{*}\left(E-\mathcal{P}_{2}\right) A x^{k}\right\|^{2} \\
= & \left\|x^{k}-p\right\|^{2}-2 \gamma_{k} \sum_{t=1}^{S_{2}} \eta_{t}\left\langle\left(E-T_{t}^{2}\right) A x^{k}-\left(E-T_{t}^{2}\right) A p, A x^{k}-A p\right\rangle \\
& \quad+\gamma_{k}^{2}\left\|A^{*}\left(E-\mathcal{P}_{2}\right) A x^{k}\right\|^{2} \\
\leq & \left\|x^{k}-p\right\|^{2}-2 \gamma_{k} q\left(x^{k}\right)+\gamma_{k}^{2}\left(\left\|A^{*}\left(E-\mathcal{P}_{2}\right) A x^{k}\right\|+\varepsilon_{k}\right)^{2} \\
= & \left\|x^{k}-p\right\|^{2}-\rho_{k}\left(2-\rho_{k}\right) \frac{q^{2}\left(x^{k}\right)}{\left(\left\|A^{*}\left(E-\mathcal{P}_{2}\right) A x^{k}\right\|+\varepsilon_{k}\right)^{2}} \leq\left\|x^{k}-p\right\|^{2} .
\end{aligned}
$$


Therefore,

$$
\begin{aligned}
\left\|x^{k+1}-p\right\| & =\left\|t_{k} \bar{\gamma}\left(f x^{k}-f p\right)+\left(E-t_{k} F\right) u^{k}-\left(E-t_{k} F\right) p-t_{k} F p+t_{k} \bar{\gamma} f p\right\| \\
& \leq t_{k} \bar{\gamma} \theta\left\|x^{k}-p\right\|+\left(1-t_{k} \tau\right)\left\|u^{k}-p\right\|+t_{k}\|F p-\bar{\gamma} f p\| \\
& \leq\left(1-t_{k}(\tau-\bar{\gamma} \theta)\right)\left\|x^{k}-p\right\|+t_{k}\|F p-\bar{\gamma} f p\| \\
& \leq \max \left\{\left\|x^{1}-p\right\|,\|F p-\bar{\gamma} f p\| /(\tau-\bar{\gamma} \theta)\right\}
\end{aligned}
$$

from which it follows the boundedness of $\left\{x^{k}\right\}$. Further, we have the following estimate

$$
\begin{gathered}
\left\|x^{k+1}-p\right\|^{2} \leq\left(1-t_{k}(\tau-\bar{\gamma} \theta)\right)\left\|x^{k}-p\right\|^{2}-\tilde{\rho} \frac{q^{2}\left(x^{k}\right)}{\left(\left\|A^{*}\left(E-\mathcal{P}_{2}\right) A x^{k}\right\|+\varepsilon_{k}\right)^{2}} \\
-2 t_{k}\left\langle F p-\bar{\gamma} f p, x^{k+1}-p\right\rangle,
\end{gathered}
$$

where $\tilde{\rho}$ is some positive constant such that $\left(1-t_{k} \tau\right) \rho_{k}\left(2-\rho_{k}\right) \geq \tilde{\rho}$ for all $k \geq 1$. We need only to consider two cases.

Case 1. $\left\|x^{k+1}-p\right\| \leq\left\|x^{k}-p\right\|$ for all $k \geq k_{0}$ large enough. Then, there exists $\lim _{k \rightarrow \infty}\left\|x^{k}-p\right\|$. From (2.5) it follows that

$$
\begin{array}{r}
0 \leq \frac{\tilde{\rho} q^{2}\left(x^{k}\right)}{\left(\left\|A^{*}\left(E-\mathcal{P}_{2}\right) A x^{k}\right\|+\varepsilon_{k}\right)^{2}} \leq\left\|x^{k}-p\right\|^{2}-\left\|x^{k+1}-p\right\|^{2} \\
-t_{k}(\tau-\bar{\gamma} \theta)\left\|x^{k}-p\right\|^{2}+2 t_{k}\|F p-\bar{\gamma} f p\|\left\|x^{k+1}-p\right\| .
\end{array}
$$

So, from (2.6), the existence of $\lim _{k \rightarrow \infty}\left\|x^{k}-p\right\|$ with the boundedness of $\left\{x^{k}\right\}$ and property of $\left\{\varepsilon_{k}\right\}$, we get that $\lim _{k \rightarrow \infty} q\left(x^{k}\right)=0$. Thus, $\lim _{k \rightarrow \infty}\left\|\left(E-T_{t}^{2}\right) A x^{k}\right\|=0$ for all $t=1, \cdots, S_{2}$, and hence,

$$
\lim _{k \rightarrow \infty}\left\|\left(E-\mathcal{P}_{2}\right) A x^{k}\right\|=0
$$

and $\lim _{k \rightarrow \infty}\left\|A^{*}\left(E-\mathcal{P}_{2}\right) A x^{k}\right\|=0$. Put $v^{k}:=-\gamma_{k} A^{*}\left(E-\mathcal{P}_{2}\right) A x^{k}$ and $z^{k}=x^{k}+v^{k}$. It is clear that $\lim _{k \rightarrow \infty} v^{k}=0$ and

Therefore,

$$
\begin{aligned}
\left\|u^{k}-p\right\|^{2} & =\left\|\mathcal{P}_{1} z^{k}-p\right\|^{2} \leq \sum_{t=1}^{S_{1}} \beta_{t}\left\|T_{t}^{1} z^{k}-p\right\|^{2} \\
& \leq\left\|z^{k}-p\right\|^{2}-\sum_{t=1}^{S_{1}} \beta_{t} \sum_{l=1}^{\gamma\left(I_{t}\right)}\left\|U^{i_{l}^{t}} z^{k}-U^{i_{l-1}^{t} z^{k}}\right\|^{2} \\
& \leq\left\|x^{k}-p\right\|^{2}+2\left\|v^{k}\right\|\left\|z^{k}-p\right\|-\sum_{t=1}^{S_{1}} \beta_{t} \sum_{l=1}^{\gamma\left(I_{t}\right)}\left\|U^{i_{l}^{t}} z^{k}-U^{i_{l-1}^{t}} z^{k}\right\|^{2} .
\end{aligned}
$$

$$
\begin{aligned}
&\left\|x^{k+1}-p\right\|^{2} \leq t_{k} \bar{\gamma} \theta\left\|x^{k}-p\right\|^{2}+\left\|x^{k}-p\right\|^{2}+2\left\|v^{k}\right\|\left\|z^{k}-p\right\| \\
& \quad-\sum_{t=1}^{S_{1}} \beta_{t} \sum_{l=1}^{\gamma\left(I_{t}\right)}\left\|U^{i_{l}^{t}} z^{k}-U^{i_{l-1}^{t}} z^{k}\right\|^{2}+2 t_{k}\|F p-\bar{\gamma} f p\|\left\|x^{k+1}-p\right\|,
\end{aligned}
$$

and hence, $\lim _{k \rightarrow \infty}\left\|U^{i_{l}^{t}} z^{k}-U^{i_{l-1}^{t}} z^{k}\right\|=0$ for all $l=1,2, \cdots, \gamma\left(I_{t}\right)$ and all $t=1,2, \cdots, S_{1}$. As in the proof of Lemma 2.1,

$$
\lim _{k \rightarrow \infty}\left\|\left(E-P_{C_{i}}\right) x^{k}\right\|=0 \forall i \in I .
$$

Since $\left\{x^{k}\right\}$ is bounded, there exists a subsequence $\left\{x^{k_{m}}\right\}$ of the sequence $\left\{x^{k}\right\}$ such that $x^{k_{m}}$ converges weakly to a point $\tilde{p} \in H_{1}$ as $m \rightarrow \infty$. Then, $A x^{k_{m}}$ also converges weakly to $A \tilde{p}$. From Lemmas 1.2 and 2.1 with (2.7) and (2.8) it follows that $\tilde{p} \in \Gamma$. Similarly, we have also that every cluster point of $\left\{x^{k}\right\}$ belongs to $\Gamma$. Therefore,

$$
\limsup _{k \rightarrow \infty}\left\langle F p_{*}-\bar{\gamma} f p_{*}, p_{*}-x^{k}\right\rangle=\lim _{m \rightarrow \infty}\left\langle F p_{*}-\bar{\gamma} f p_{*}, p_{*}-x^{k_{m}}\right\rangle=\left\langle F p_{*}-\bar{\gamma} f p_{*}, p_{*}-\tilde{p}\right\rangle \leq 0,
$$

where $p_{*}$ is a unique solution of $p_{*} \in \Gamma:\left\langle F p_{*}-\bar{\gamma} f p_{*}, p_{*}-p\right\rangle \leq 0 \forall p \in \Gamma$. Now, from (2.5) we have that

$$
\left\|x^{k+1}-p_{*}\right\|^{2} \leq\left(1-t_{k}(\tau-\bar{\gamma} \theta)\right)\left\|x^{k}-p_{*}\right\|^{2}+2 t_{k}\left\langle F p_{*}-\bar{\gamma} f p_{*}, p_{*}-x^{k+1}\right\rangle .
$$

By Lemma 1.3, $\left\|x^{k}-p_{*}\right\| \rightarrow 0$ as $k \rightarrow \infty$. 
Case 2. There exists a subsequence $\left\{k_{l}\right\}$ of $\{k\}$ such that $\left\|x^{k_{l}}-p\right\|<\left\|x^{k_{l}+1}-p\right\|$ for all $l \geq 0$. Hence, by Lemma 1.5, there exists a nondecreasing sequence $\left\{m_{k}\right\} \subseteq\{k\}$ such that $m_{k} \rightarrow \infty$,

$$
\left\|x^{m_{k}}-p\right\| \leq\left\|x^{m_{k}+1}-p\right\| \quad \text { and }\left\|x^{k}-p\right\| \leq\left\|x^{m_{k}+1}-p\right\|
$$

for each $k \geq 1$. Then, from (2.5) and the first inequality in (2.9), we know that

$$
\left\|x^{m_{k}}-p\right\|^{2} \leq(2 /(\tau-\bar{\gamma} \theta))\left\langle F p-\bar{\gamma} f p, p-x^{m_{k}+1}\right\rangle .
$$

In this case, instead of (2.6), we get that

$$
0 \leq \frac{\tilde{\rho} q^{2}\left(x^{m_{k}}\right)}{\left.\left\|A^{*}\left(E-\mathcal{P}_{2}\right) A x^{m_{k}}\right\|+\varepsilon_{m_{k}}\right)^{2}} \leq 2 t_{m_{k}}\|F p-\bar{\gamma} f p\|\left\|x^{m_{k}+1}-p\right\|
$$

and hence, $\lim _{k \rightarrow \infty} q\left(x^{m_{k}}\right)=0$. By the similar argument as in the proof for the case 1 , $\lim _{k \rightarrow \infty}\left\|\left(E-\mathcal{P}_{2}\right) A x^{m_{k}}\right\|=0$ and $\lim _{k \rightarrow \infty}\left\|\left(E-P_{C_{i}}\right) x^{m_{k}}\right\|=0$ for all $i \in I$ and any cluster point of $\left\{x^{m_{k}}\right\}$ belongs to $\Gamma$. Thus, $\lim _{\sup _{k \rightarrow \infty}}\left\langle F p_{*}-\bar{\gamma} f p_{*}, p_{*}-x^{m_{k}+1}\right\rangle \leq 0$, which together with (2.10) implies that $\left\|x^{m_{k}}-p_{*}\right\| \rightarrow 0$ as $k \rightarrow \infty$. Now, from (2.5) with $k$ and $p$ replaced, respectively, by $m_{k}$ and $p_{*}$ it follows that $\left\|x^{m_{k}+1}-p_{*}\right\| \rightarrow 0$. Noting the second inequality in (2.9), $\left\|x^{k}-p_{*}\right\| \rightarrow 0$.

In the case that $\theta=0, \bar{\gamma}=0$. Hence, (2.2) has the expression

$$
x^{k+1}=\left(E-t_{k} F\right) \mathcal{P}_{1}\left(E-\gamma_{k} A^{*}\left(E-\mathcal{P}_{2}\right) A\right) x^{k} .
$$

Replacing $\bar{\gamma}=0$ in the proof when $\bar{\gamma} \neq 0$, we obtain the conclusion. The proof is completed. $\square$ Remark 2.2 It is easy to see that $F=E-f$ is also $\eta$-strongly monotone and $\gamma$-strictly pseudocontractive such that $\eta+\gamma>1$, where $f=a E+(1-a) u$ with a fixed $u \in H_{1}$ and $a \in(0,1)$. Then, replacing $F=E-f$ in $(2.11)$, we obtain a modified Halpern's algorithmic scheme,

with a new $t_{k}:=(1-a) t_{k}$.

$$
x^{k+1}=t_{k} u+\left(1-t_{k}\right) \mathcal{P}_{1}\left(E-\gamma_{k} A^{*}\left(E-\mathcal{P}_{2}\right) A\right) x^{k},
$$

From Theorem 2.2, we have the following result for the strong convergence of Halpern's algorithmic scheme (2.12) with (2.3).

Theorem 2.3 Let $H_{1}, H_{2}, A, C_{i}$ and $Q_{j}$ with $\Gamma$ be as in Theorem 2.1. Assume that there hold conditions $(\rho),(\varepsilon)$ and $(t)$. Then, the sequence $\left\{x^{k}\right\}$, defined by the algorithmic scheme (2.12) with $\gamma_{k}$ defined in Algorithmic scheme 2 , converges strongly to a point in $\Gamma$, as $k \rightarrow \infty$.

\section{Conclusion}

In this paper, to solve the multiple-sets split feasibility problem (MSSFP) in Hilbert spaces, we proposed two string-averaged algorithmic schemes, one of which was given with the strong convergence and a self-adaptive step-size. We also considered the particular case of the proposed schemes.

Acknowledgements This paper is the product of Grassroots level scientific and technological project of Foreign Trade University: "Some methods for finding a zero of a maximal monotone mapping and a solution of the split feasibility problem" with the code NTCS2021-22 by PhD Nguyen Duong Nguyen-the project manager.

\section{REFERENCES}

[1] Y. Censor Y and T. Elfving, "A multiprojection algorithm using Bregman projections in a product spaces," Numer. Algorithms, vol. 8, pp. 221-239, 1994.

[2] C. Byrne, "Iterative oblique projection onto convex sets and the split feasibility problem," Inverse Problems, vol. 18, no. 2, pp. 441-453, 2002.

[3] C. Byrne, "A unified treatment of some iterative algorithms in signal processing and image reconstruction," Inverse Problems, vol. 20, pp. 103-120, 2004. 
[4] Y. Censor, T. Bortfeld, B. Martin, and A. Trofimov, "A unified approach for inverse problems in intensity-modulated radiation therapy," Phys. Med. Biol., vol. 51, pp. 23532365, 2006.

[5] Y. Censor, T. Elfving, N. Knop, and T. Bortfeld, "The multiple-sets split feasibility problem and its applications for inverse problems," Inverse Problems, vol. 21, pp. 2071-2084, 2005.

[6] Ng. Buong, "Iterative algorithms for the multiple-sets split feasibility problem in Hilbert spaces," Numer. Algorithms, vol. 76, no. 3, pp. 783-789, 2017.

[7] Ng. Buong, P. T. T. Hoai, and K. T. Binh, "Iterative regularization methods for the multiple-sets split feasibility problem in Hilbert spaces," Acta Math. Appl., vol. 165, no. 1, pp. 183-197, 2020.

[8] J. Wang, Y. Hu, C. K. W. Yu, and X. Zhuang, "A family of projection gradient methods for solving the multiple-sets split feasibility problem," J. Optim. Theory Appl., vol. 183, pp. 520-534, 2019.

[9] M. Wen, J. Peng, and Y. Tang, "A cyclic and simultaneous iterative method for solving the multiple-sets split feasibility problem," J. Optim. Theory Appl., vol. 166, pp. 844-860, 2015.

[10] H. K. Xu, "A variable Krasnosel'skii-Mann algorithm and the multiple-set split feasibility problem," Inverse Problems, vol. 22, pp. 2021-2034, 2006.

[11] W. Zhang, D. Han, and Zh. Li, "A self-adaptive projection method for solving the multiplesets split feasibility problem," Inverse Problems, vol. 25, 115001, 16 pp, 2009.

[12] J. Zhao and Q. Yang, "A simple projection method for solving the multiple-sets split feasibility problem," Inverse Probl. Sci. Eng., vol. 21. pp. 537-546, 2013.

[13] J. Zhao, Y. Zhang, and Q. Yang, "Modified projection methods for the split feasibility problem and the the multiple-sets split feasibility problem," Appl. Math. Comput., vol. 219, pp. 1644-1653, 2012.

[14] Y. Censor, T. Elfving, and G. T. Herman, "Averaging strings of sequential iterations for convex feasibility problems," in Inherently parallel algorithms in feasibility and optimization and their applications (Haifa, 2000) Stud. Comput. Math., 8, North-Holland, Amsterdam, 2001, pp. 101-113.

[15] G. Marino and H. K. Xu, "A general iterative method for nonexpansive mappings in Hilbert spaces," J. Math. Anal. Appl., vol. 318, pp. 43-52, 2006.

[16] P. L. Combettes and I. Yamada, "Compositions and convex combinations of averaged nonexpansive operators," J. Math. Anal. Appl., vol. 425, pp. 55-70, 2015.

[17] K. Goebel and W. A. Kirk, Topics in Metric Fixed Point Theory, vol. 28, Cambridge University Press. Cambridge, UK, 1990.

[18] H. K. Xu, "An iterative approach to quadratic optimization," J. Optim. Theory Appl., vol. 116, pp. 659-678, 2003.

[19] L. C. Ceng, Q. H. Ansari, and J. Ch. Yao, "Mann-type steepest-descent and modified hybrid steepest descent methods for variational inequalities in Banach spaces," Num. Funct. Anal. Optim., vol. 29, no. 9-10, pp. 987-1033, 2008.

[20] P. E. Maingé, "Strong convergence of projected subgradient methods for nonsmooth and nonstrictly convex minimization," Set-Valued Var. Anal., vol. 16, pp. 899-912, 2008.

[21] W. Takahashi and M. Toyoda, "Weak convergence theorems for nonexpansive mappings and monotone mappings," J. Optim. Theory and Appl., vol. 118, no. 2, pp. 417-428, 2003.

[22] W. Takahashi, H. K. Xu, and J. -C. Yao, "Iterative methods for generalized split feasibility problems in Hilbert spaces," Set-Valued Var. Anal., vol. 23, pp. 205-221, 2015. 